\title{
SINUS BRADYCARDIA IN A YOUNG FEMALE
}

\author{
Elena-Codruța DOBRICĂ ${ }^{1}$, Mihnea-Alexandru GĂMAN ${ }^{1} \bowtie$, Matei-Alexandru COZMA ${ }^{1}$, \\ Florentina GHERGHICEANU ${ }^{1}$, Anca PANTEA STOIAN ${ }^{1}$, Bogdan SOCEA ${ }^{1,2}$, \\ Ana Maria A. STĂNESCU ${ }^{1}$, Ovidiu G. BRATU ${ }^{1,3}$, Tiberiu P. NEAGU ${ }^{1,4}$, Camelia C. DIACONU ${ }^{1,5}$ \\ ${ }^{1}$ „Carol Davila“ University of Medicine and Pharmacy, Bucharest, Romania \\ ${ }^{2}$ General Surgery Clinic, Emergency Clinical Hospital „Sfântul Pantelimon“, Bucharest, Romania \\ ${ }^{3}$ Department of Urology, Emergency Universitary Central Military Hospital, Academy of Romanian \\ Scientists, Bucharest, Romania \\ ${ }^{4}$ Plastic Surgery Clinic, Clinical Emergency Hospital of Bucharest, Romania \\ ${ }^{5}$ Internal Medicine Clinic, Clinical Emergency Hospital of Bucharest, Bucharest, Romania
}

Received 17 Sept 2018, Accepted 23 Oct 2018

https://doi.org/10.31688/ABMU.2018.53.4.20

\section{Abstract}

Introduction. Primary cardiac tumours are very rare neoplasms, usually with a late diagnosis in clinical practice, because of nonspecific symptoms and clinical signs.

Case presentation. We report the case of a 28-yearold woman, who presented for right flank and right iliac fossa pain, radiating to the right lower limb. The pain was progressive and had had its onset 3-4 days previously. The patient was known with renal calyceal microlithiasis (with renal colic in the history) and mild iron deficiency anaemia, and had a medical history of recurrent miscarriages. Physical examination revealed: sinus bradycardia (50-54 bpm), low-grade fever, and positive Giordano sign on the right side. The pain was considered as right renal colic and analgesics and antispasmodics were administered. Blood tests revealed normocytic, hypochromic anaemia and a mild inflammatory syndrome. Abdominal ultrasound revealed bilateral renal microlithiasis and also a triangular, hypoechoic area in the right kidney parenchyma, with no colour Doppler ultrasound signals. Echocardiography revealed a left atrial mass with a diameter of $1.5 \mathrm{~cm}$,

\section{RÉSUMÉ}

Bradycardie sinusale chez une jeune femme

Introduction. Les tumeurs cardiaques primitives sont des entités cliniques relativement rares avec un diagnostic tardif en raison de manifestations non spécifiques.

Rapport du cas. Une femme de 28 ans, non-fumeuse, a été admise à notre hôpital avec une douleur dans la région latérale droite et dans la fosse iliaque droite irradiant vers le membre inférieur ipsilatéral. La douleur était progressive et a commencé il y a quelques jours. La patiente a dans ses antécédents médicaux une fausse couche, une micro lithiase rénale et une anémie faible. L'examen physique révèle une fièvre légère, une bradycardie sinusale $(50-54 \mathrm{bpm})$ et le signe de Giordano positif sur le côté droit. La patiente a été diagnostiquée avec une colique rénale droite et traitée avec des analgésiques et des antispasmodiques. Les analyses biochimiques ont révélé une anémie normocytaire hypochrome et un syndrome inflammatoire. Une échographie abdominale a été effectuée montrant une micro lithiase rénale et une zone de parenchyme triangulaire et hypoéchogène sans signal d'échographie 
hyperechoic, heterogeneous, mobile, attached to the interatrial septum. Chest-abdomen-pelvis CT confirmed the presence of the cardiac mass, as well as an area of right renal infarction. Anticoagulant therapy with low molecular weight heparin was initiated. The patient was referred to the cardiovascular surgery department, where the cardiac mass was removed and sent for histological examination, which confirmed the diagnosis of left atrial myxoma. The patient had a favourable evolution.

Conclusions. The presence of sinus bradycardia in a young patient, without known cardiac diseases, led to the necessity of an echocardiography, which revealed the left atrial mass. Peripheral embolization with right kidney infarction represented the clinical onset of the cardiac tumour. In this patient, who presented with abdominal and right flank pain, the previous known diagnosis of renal microlithiasis was initially misleading. Cardiac tumours have unspecific symptoms and the first manifestations could be due to the embolization of tumour fragments in the periphery, mimicking, thus, other disorders.

Keywords: atrial myxoma, sinus bradycardia, peripheral embolization, renal infarction, renal colic, heart tumours.

\section{INTRODUCTION}

Primary cardiac tumours are relatively rare and the most frequent is atrial myxoma which accounts for approximately $50 \%$ of cases ${ }^{1}$. Atrial myxoma is a benign tumour found especially in adults over the age of 60 . It can be discovered in various sites: left atrium, right atrium or the two ventricles. It most commonly affects the left atrium, with a particular predisposition for the interatrial septum ${ }^{1,2}$. The incidence of atrial myxoma varies based on sex: left atrial myxoma is twofold more frequent in women vs. men, whereas right atrial myxoma can be discovered in both sexes in a similar percentage ${ }^{3}$.

Atrial myxomas can lead to the development of various clinical signs, yet the typical one is dyspnoea. Other clinical manifestations are arrhythmias, peripheral edema and those related to embolic complications or valvular involvement $t^{4,5}$.

\section{Case Presentation}

A 28-year-old female, non-smoker, is admitted to the Internal Medicine Clinic for pain in the right flank and right iliac fossa, extending to the ipsilateral
Doppler dans le rein droit. Léchocardiographie a révélé une masse auriculaire gauche d'un diamètre de $1.5 \mathrm{~cm}$, hyperéchogène, hétérogène, mobile, attachée au septum inter-atrial. Le scanner de thorax-abdomen-pelvis a confirmé la masse cardiaque ainsi qu'une zone d'infarctus du rein droit. Le traitement anticoagulant a été initié. Le risque cardiaque préopératoire a été évalué et le patient a été dirigé vers le service de chirurgie cardiovasculaire où la masse cardiaque a été prélevée. L'examen histologique a confirmé le diagnostic de myxome auriculaire gauche. L'évolution du patient était favorable.

Conclusions. La particularité de ce cas est représentée par la symptomatologie spécifique d'une colique rénale chez une patiente présentant des antécédents médicaux de micro lithiase, suggérant une maladie rénale. La présence d'une bradycardie sinusale chez un jeune patient a nécessité une échocardiographie qui a révélé la masse auriculaire gauche. L’embolisation périphérique, qui avait conduit à un infarctus du rein droit, était le début clinique dans ce cas de myxome auriculaire. Les tumeurs cardiaques ont une symptomatologie non spécifique et les premières manifestations pourraient être dues à l'embolisation des fragments tumoraux à la périphérie, imitant ainsi d'autres pathologies.

Mots-clés: myxome auriculaire, bradycardie sinusale, embolisation périphérique, infarctus rénal, colique rénale, tumeurs cardiaques.

inferior limb. The pain was progressive and had had its onset a couple of days ago. The medical history of the patient included: miscarriage in the $6^{\text {th }}$ week of pregnancy, renal calyceal microlithiasis and mild iron-deficiency anaemia. The patient also related multiple episodes of renal colic on the basis of calyceal microlithiasis. The clinical examination highlighted the following abnormal findings: low-grade fever, sinus bradycardia (pulse rate 52 beats/minute), right flank pain and positive Giordano sign on the right side.

Evaluation by electrocardiography revealed sinus bradycardia (heart rate $50-54$ beats/minute), as shown in Figure 1. All other characteristics were in normal limits.

The diagnosis of right renal colic was established and the patient was hospitalized and treated with analgesics and antispasmodics. Blood tests revealed mild normocytic, hypochromic anaemia and low-grade inflammatory syndrome. Abdominal ultrasound revealed renal calyceal microlithiasis and a triangular, hypoechoic area of parenchyma with no Doppler ultrasound signal in the right kidney. The presence of sinus bradycardia in a young female with no significant medical history was initially attributed to vagal stimulation caused by the abdominal pain. 


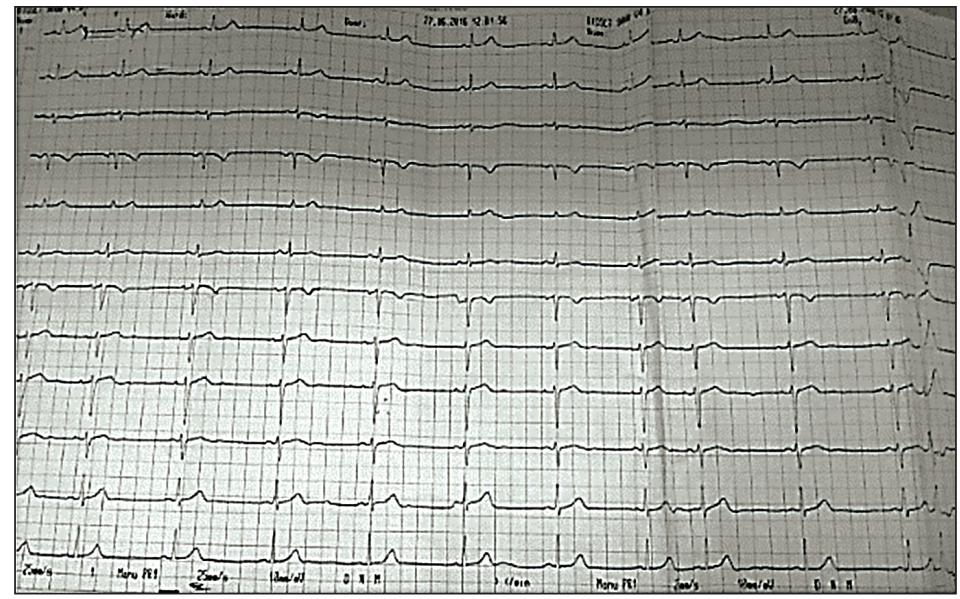

Figure 1. Electrocardiography on admission: sinus bradycardia.

Echocardiography was decided and a left atrial mass with a diameter of $1.5 \mathrm{~cm}$, hyperechoic, heterogeneous, mobile, with irregular contour was discovered. The mass was attached to the interatrial septum and had the tendency to prolapse in the left ventricle during diastole (Figure 2).

Chest-abdomen-pelvis CT confirmed the cardiac mass, as well as an area of right renal infarction. Anticoagulant treatment with low molecular weight heparin was initiated. Preoperative cardiac risk was assessed and the patient was referred to the cardiovascular surgery department where the cardiac mass was removed (Figure 3). Histological examination confirmed the left atrial myxoma diagnosis. The evolution of the patient was favourable.

\section{Discussion}

In most cases, due to unspecific symptomatology or even absence of symptoms, diagnosis of atrial myxoma is late and established in patients over 60 years old. The most common symptom for which patients present to the hospital is dyspnoea, especially when the atrial myxoma is located near the mitral orifice. In this situation, the heart mass can lead to the obstruction of the mitral orifice and, subsequently, to the development of heart failure-related symptomatology $^{1}$. Also, in over $80 \%$ of cases, the clinical examination of the cardiovascular system by auscultation can reveal heart murmurs ${ }^{6}$.

Other symptoms and signs may be: arrhythmias, syncope or a clinical picture arisen from the peripheral embolization of tumour fragments (as in the case of our patient, who was diagnosed with renal infarction) ${ }^{7-8}$. Embolic events are the second most common complications after the obstruction of the mitral orifice ${ }^{9}$. Arrhythmias due to atrial myxoma can sometimes be non-life-threatening, such as the sinus bradycardia described in this report, or even take the form of sudden cardiac death ${ }^{7,9,10}$.
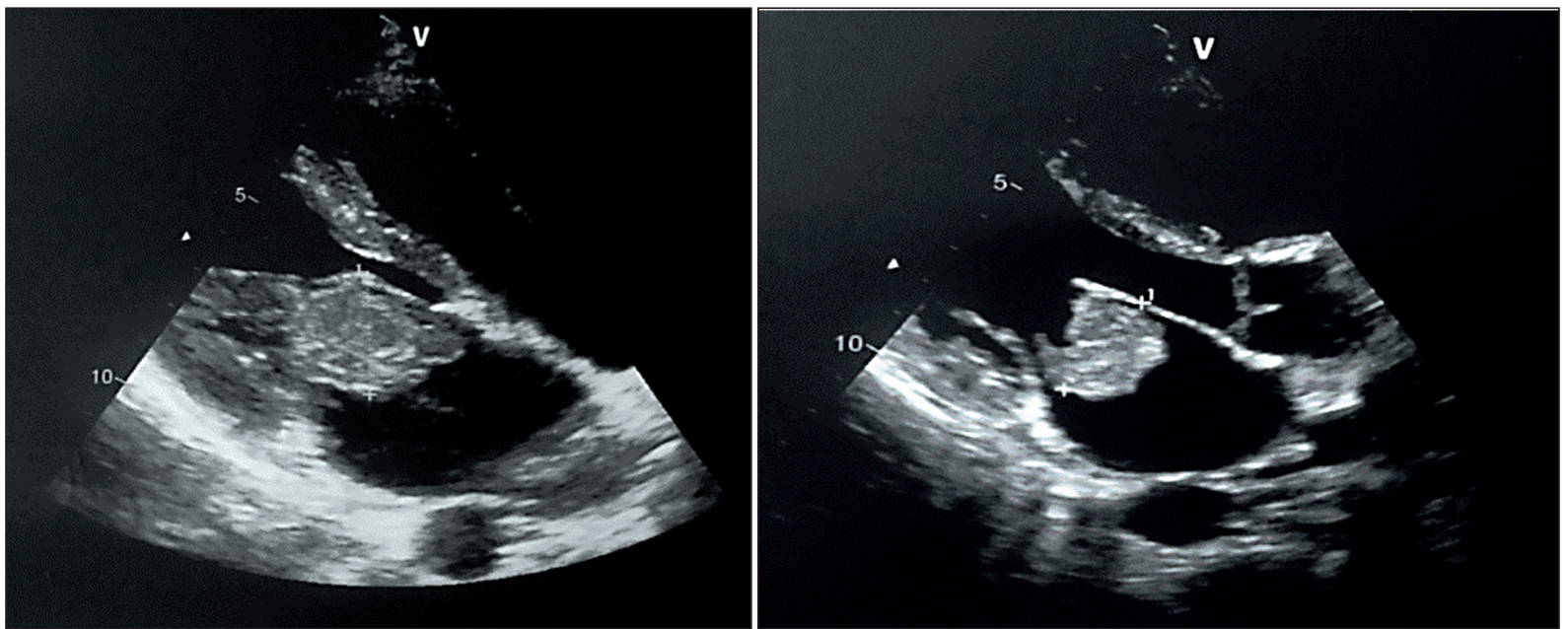

Figure 2. 2D transthoracic echocardiogram: left atrial mass attached to the interatrial septum. 

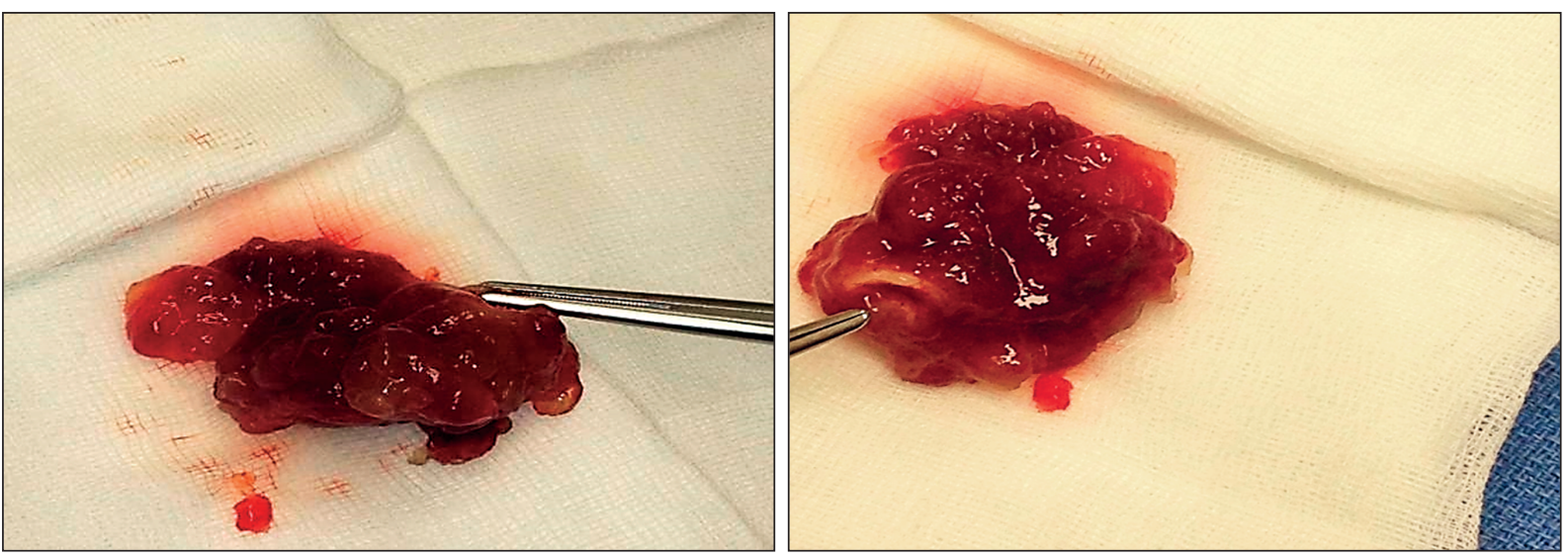

Figure 3. Gross examination of the left atrial mass following surgical removal.

In the case of our patient, the presence of sinus bradycardia at the clinical examination and on the electrocardiogram in a young patient without cardiovascular risk factors determined us to recommend transthoracic echocardiography.

A report published in 2001 that analysed clinical findings in 112 patients diagnosed with left atrial myxoma evidenced that sinus bradycardia is more frequent than sinus tachycardia or other arrythmias ${ }^{11}$. Moreover, embolic complications were seen in a higher percentage in young men rather than in women. In females, the most common age group affected by atrial myxoma was $40-70$ years old, whereas in men all age groups were equally interested ${ }^{11}$. Furthermore, a similar study from 2002 highlighted that sinus tachycardia is a risk factor for peripheral embolization of tumour fragments, as well as tumour involvement of the mitral valve and tumour prolapse via the mitral orifice $^{12}$. Over $90 \%$ of patients that suffer embolic complications meet at least two of the three aforementioned criteria: sinus tachycardia, tumour involvement of the mitral valve or tumour prolapse via the mitral orifice ${ }^{9}$. The presence of sinus bradycardia, however, might be explained by the tumour prolapse via the mitral orifice, which leads to a prolongation of the diastole.

Benign heart tumours can be associated with benign or malignant arrhythmias that can have a recurrent character and persist even after surgical excision of the mass. This can be due either to tumour extension to anatomical structures, which do not allow the complete resection in terms of safety (the surgical risks are higher than the benefits of the procedure) or due to tumour involvement of the conducting tissue of the heart ${ }^{13}$. Currently, no risk stratification system for malignant arrhythmias has been proposed and there are no clear instructions in the guidelines of the European Society of Cardiology (ESC) regarding the need for an implantable defibrillator in such cases.
Moreover, the presence of arrhythmias, and atrial fibrillation in particular, has often been associated with the occurrence of large atrial myxomas ${ }^{14}$.

The peculiarity of this case report resides in the specific symptomatology for a renal colic in a patient with a medical history of renal calyceal microlithiasis, which initially oriented the diagnosis towards a kidney disease. At the same time, the discovery of persistent sinus bradycardia in a young female with no cardiovascular risk factors justified the echocardiography request revealing the left atrial mass. Peripheral embolization, which had led to a right renal infarction, was the clinical onset in this case of atrial myxoma.

\section{Conclusions}

Cardiac tumours can have unspecific manifestations, thus mimicking other diseases. The first symptoms and signs can sometimes develop due to peripheral embolization of tumour fragments. Despite the uncharacteristic symptomatology, heart tumours can cause severe complications and even sudden cardiac death. Early diagnosis can increase the success rate of surgery and improve the prognosis of the patients. Comorbidities may have a role in the prognosis of these patients ${ }^{15-17}$.

\section{Acknowledgements:}

The authors express their gratitude to all the physicians involved in the management of the case: radiologists, intensivists, cardiac surgeons.

\section{Compliance with Ethics Requirements:}

„The authors declare no conflict of interest regarding this article"

"The authors declare that all the procedures and experiments of this study respect the ethical standards in the 
Helsinki Declaration of 1975, as revised in 2008(5), as well as the national law. Informed consent was obtained from the patient included in the study"

"No funding for this study"

\section{References}

1. Thyagarajan B, Kumar MP, Patel S, Agrawal A. Extracardiac manifestations of atrial myxomas. J Saudi Heart Assoc 2017;29(1):37-43.

2. Diaconu C. Atrial septal defect in an elderly woman - a case report. Journal of Medicine and Life 2011;4(1):91-93.

3. Li H, Guo H, Xiong H, et al. Clinical features and surgical results of right atrial myxoma. J Card Surg 2015;31(1):15-17.

4. Goswami KC, Shrivastava S, Bahl VK, et al. Cardiac myxomas: clinical and echocardiographic profile. Int J Cardiol 1998;63(3): 251-9.

5. Diaconu CC, Arsene D, Paraschiv B, Bălăceanu A, Bartoș D. Hyponatremic encephalopathy as the initial sign of neuroendocrine small cell carcinoma - case report. Acta Endocrinologica 2013;IX(4): 637-642.

6. Aggarwal SK, Ramachandra B, Sarma MA, et al. Clinical presentation and investigation findings in cardiac myxomas: new insights from the developing world. Am Heart J 2007;154(6):1102-1107.

7. Garatti A, Nano G, Canziani A, et al. Surgical excision of cardiac myxomas: twenty years experience at a single institution. Ann Thorac Surg 2012;93(3):825-31.
8. Hoffmeier A, Sindermann JR, Scheld HH, Martens S. Cardiac tumors - diagnosis and surgical treatment. Dtsch Arztebl Int 2014;111(12):205-11.

9. Diaconu CC, Manea M, Iancu MA, et al. Hyponatremia in patients with heart failure: a prognostic marker. Rev Chim (Bucharest) 2018; 69(5):1071-1074.

10. Diaconu CC, Stanescu AMA, Pantea Stoian A, et al. Hyperkalemia and cardiovascular diseases: new molecules for the treatment. Rev Chim (Bucharest) 2018; 69(6):1367-1370.

11. Pinede L, Duhaut P, Loire R. Clinical presentation of left atrial cardiac myxoma. A series of 112 consecutive cases. Medicine (Baltimore) 2001;80(3):159-72.

12. Keeling IM, Oberwalder P, Anelli-Monti M, et al. Cardiac myxomas: 24 years of experience in 49 patients. Eur J Cardiothorac Surg 2002;22(6):971-7.

13. Myers KA, Wong KK, Tipple M, Sanatani S. Benign cardiac tumors, malignant arrhythmias. Can J Cardiol 2010;26(2): e58-e61.

14. Acebo E, Val-Bernal JF, Gomez-Roman JJ, Revuelta JM. Clinicopathologic study and DNA analysis of 37 cardiac myxomas: a 28-year experience. Chest 2003;123(5):1379-1385.

15. Diaconu CC, Dragoi CM, Bratu OG, et al. New approaches and perspectives for the pharmacological treatment of arterial hypertension. Farmacia 2018; 66(3):408-415.

16. Diaconu CC, Dediu GN, Iancu MA. Drug-induced arterial hypertension, a frequently ignored cause of secondary hypertension: a review. Acta Cardiologica, 2018. DOI 10.1080/00015385.2017.1421445.

17. Diaconu C, Bălăceanu A, Moroșan E. Sepsis biomarkers: past, present and future. Farmacia 2015, 63(6):811-815. 